\title{
Transfer of warrant, begging the question and semantic externalism
}

DOI:

$10.1111 / 1467-9213.00234$

\section{Document Version}

Accepted author manuscript

Link to publication record in Manchester Research Explorer

\section{Citation for published version (APA):}

Beebee, H. (2001). Transfer of warrant, begging the question and semantic externalism. Philosophical Quarterly, 51(204), 356-374. https://doi.org/10.1111/1467-9213.00234

\section{Published in:}

Philosophical Quarterly

\section{Citing this paper}

Please note that where the full-text provided on Manchester Research Explorer is the Author Accepted Manuscript or Proof version this may differ from the final Published version. If citing, it is advised that you check and use the publisher's definitive version.

\section{General rights}

Copyright and moral rights for the publications made accessible in the Research Explorer are retained by the authors and/or other copyright owners and it is a condition of accessing publications that users recognise and abide by the legal requirements associated with these rights.

\section{Takedown policy}

If you believe that this document breaches copyright please refer to the University of Manchester's Takedown Procedures [http://man.ac.uk/04Y6Bo] or contact uml.scholarlycommunications@manchester.ac.uk providing relevant details, so we can investigate your claim.

\section{OPEN ACCESS}




\section{Transfer of Warrant, Begging the Question and Semantic Externalism ${ }^{1}$}

\section{Helen Beebee,}

Please do not cite this version. The published version is:

'Transfer of Warrant, Begging the Question and Semantic Externalism', Philosophical Quarterly 51 (2000), 356-74

\section{The problem - and Davies' solution}

In a recent paper (Davies 1998), Martin Davies offers a novel solution to the problem of the alleged incompatibility between semantic externalism and first person authority. Roughly speaking, the problem arises from arguments like the following (W):

(W1) I am having a water thought

(W2) If I am having a water thought, then I live in a water world

Therefore

(W3) I live in a water world

If I know (W1) by first person authority, and I know (W2) by conceptual analysis, it seems to follow that I can know (W3), an empirical proposition, without needing to conduct any empirical investigation whatever. Since this is absurd, incompatibilists claim, one of the premises that generate the absurdity - namely first person authority

\footnotetext{
${ }^{1}$ Many thanks to Martin Davies for some interesting and helpful discussions of previous drafts. Thanks also to Josh Parsons, Mike Martin, Sarah Sawyer, Crispin Wright, the Research Seminar audience at the Research School of Social Sciences, Australian National University, and the referees for this journal.
} 
and semantic externalism - must be false. (This is a very rough and ready characterisation of the problem, but it will do for the purposes of this paper.)

Davies' compatibilist solution to the problem is to deny that warrant can be transferred from the premises of (W) to its conclusion. So, although (W1) is indeed warranted by first person authority, and (W2) is indeed warranted by semantic externalism, we may not transfer this warrant across to (W3). While we may in fact be independently warranted in believing (W3), we cannot acquire any warrant for it by making use of (W).

Davies' central claim is that (W) is but one instance of a whole class of arguments whose conclusions have what might be called "preconditional status" with respect to one of the premises. In the case of $(\mathrm{W})$, my being in a water world is a precondition of my even being able to entertain (W1). In other cases, the truth of the conclusion is a precondition of my genuinely having warrant for one of the premises. In both kinds of case, Davies argues, warrant cannot be transferred from premises to conclusion. And he formulates a pair of "limitation principles" which state the conditions under which warrant may not be transferred.

My modest aim in this paper is to show that while Davies is no doubt right about the preconditional status of the conclusions of such arguments, and also right to think that such arguments are, in some sense, unconvincing, he does not provide any motivation for diagnosing their failure to convince as failure of warrant transfer. I argue that what's wrong with (W) and its ilk is that they beg the question against those who take themselves to have reasons to doubt their conclusions. I show that question begging 
and failure of warrant transfer are not the same, and that Davies' arguments in fact only point towards the conclusion that arguments like (W) beg the question. Hence his compatibilist solution to the problem of externalism and first person authority lacks adequate motivation.

My rather less modest aim is to show that no limitation principles are needed in order to rebut the incompatibilist challenge. Once we realise that the prospects for transmitting warrant from (W)'s premises to its conclusion are extremely limited even in the absence of any limitation principles, it becomes rather hard to see what the problem about first person authority and semantic externalism is supposed to be.

\section{Warrant transfer and question begging}

Davies introduces his Limitation Principles by discussing anti-sceptical arguments of the form made famous by G.E. Moore. Here is Davies' formulation (M):

(M1) This is a hand before me

(M2) If this is a hand before me, then there is an external world

Therefore:

(M3) There is an external world

Most philosophers agree that (M) completely fails to refute scepticism. But why does it fail? Davies' diagnosis is this: 
The sceptic begins by allowing that we can, indeed, know (M2). But still, we cannot arrive at knowledge of (M3) by inference from (M1) in the case where that latter piece of knowledge is warranted by sensory experience. For the sensory experience supports (M1) only in the context of our prior commitment to (M3). As Wittgenstein himself might have said ... : 'It strikes me as if someone who doubts the existence of the external world is impugning the nature of all sensory evidence.' Or, as Wright puts it (1985, p.437): 'Once the hypothesis is seriously entertained that it is as likely as not, for all I know, that there is no material world as ordinarily conceived, my experience will lose all tendency to corroborate the particular propositions about the material world which I normally take to be certain.' (1998, 350; premises renamed)

The idea here, then, is that we have to take (M3) to be true in order to count ourselves as warranted in believing (M1): doubting (M3) undermines our warrant for (M1). And Davies uses this observation to motivate his First Limitation Principle:

\section{First Limitation Principle:}

Epistemic warrant cannot be transferred from $\mathrm{A}$ to $\mathrm{B}$, even given a priori known entailment from $\mathrm{A}$ to $\mathrm{B}$, if the truth of $\mathrm{B}$ is a precondition of our warrant for A counting as a warrant. $(1998,351)$

I want to argue that Davies' diagnosis of the failure of (M) does not in fact provide any motivation for the First Limitation Principle; and the reason is that he fails to distinguish between two ways in which an argument can fail to convince. An argument can fail to convince in the sense that warrant cannot be transferred from premises to conclusion, or it can fail to convince by being incapable of persuading someone who doubts the conclusion. Davies' diagnosis of (M) shows that (M) fails to 
convince in this second sense; but arguments that fall foul of the First Limitation Principle (if there are any) are those that fail to convince in the first sense. So the fact that $(\mathrm{M})$ is unconvincing does not lend any plausibility to the claim that, in some cases, epistemic warrant is not transferred from premises to conclusion of a valid argument.

In order to see the distinction between the two kinds of failure to convince, imagine that you are a sceptic. You will not, if you are a sensible sceptic, be persuaded by (M) to renounce your scepticism; and for precisely the reason suggested by Wright and endorsed by Davies: if you seriously doubt the conclusion, you will not take yourself to be justified in believing the first premise, since you will not regard what we ordinarily take to be warrant for that premise (namely, sensory experience) as warrant for the premise.

The First Limitation Principle, however, blocks the transfer of warrant from premises to conclusion: if true, it applies to arguments whose premises we take ourselves to have warrant for, and tells us that we may not legitimately thereby take ourselves to have warrant for the conclusion. But the sceptic is not in the position of taking herself to have warrant for the premises: (M) fails to convince her precisely because there is no way to get her to take the premises to be warranted.

(M), then, fails to convince in the sense that it cannot persuade a rational doubter of the conclusion: not because the doubter may not transfer warrant across from premises to conclusion, but because the rational doubter will not accept that she has warrant for the premises in the first place. 
According to Frank Jackson, failure to convince in this second sense - that is, failure to convince a rational doubter of the conclusion - is what makes an argument beg the question. ${ }^{2}$ For Jackson, when an ideally rational being presents a valid argument, she implicitly offers evidence of a certain kind for her premises. The details of Jackson's account of implicitly offered evidence need not concern us here; all we need to know for present purposes is that if someone runs (M), the evidence that is implicitly offered for (M1) is perceptual evidence. Jackson claims that an argument is question begging just if anyone who sanely doubted the conclusion would not regard the evidence that is implicitly offered for the premises as evidence. So, as Jackson notes, according to his account arguments like (M) are question begging: a sceptic about (M3) would not count the perceptual evidence implicitly offered in support of (M1) as evidence.

If Jackson's account is right, then - and I assume in what follows that it is - we can identify what is wrong with (M) without ever raising the issue of transfer of warrant. We can diagnose $(\mathrm{M})$ as question begging in a way that simply does not touch on the question of whether warrant can be transferred from its premises to its conclusion. Just because (M) fails to convince a sceptic, nothing at all follows about whether or not someone who does regard the premises as warranted is entitled to transfer that warrant across to (M3).

One might try to claim at this point that although there are indeed two senses in which an argument can fail to convince, arguments that fail to convince in the sense that

\footnotetext{
${ }^{2}$ See Jackson (1987), Chapter 6
} 
they beg the question just are arguments that fail to transmit warrant. In the absence of any reason to suppose that the two senses come apart, we can legitimately claim that they are co-extensive, and hence that the failure of $(\mathrm{M})$ to convince the sceptic can be used in indirect support for the First Limitation Principle.

However, I think it can be shown that the two senses do come apart. To see this, consider the following argument (A):

(A1) The Australian says that the Crows won the Grand Final

(A2) If The Australian says that the Crows won the Grand Final, then the Crows won the Grand Final

Therefore:

(A3) The Crows won the Grand Final

(A), of course, is a perfectly straightforward argument, which might easily - and legitimately - convince a normal person that the Crows won the Grand Final. But consider trying to run (A) in the face of a die-hard sceptic. The sceptic will, of course, doubt the conclusion, since if she doubts the existence of the world she will likewise doubt the existence of Australian rules football teams. And (A) cannot convince the sceptic to believe (A3) because, as with (M), the sceptic's reasons for doubting (A3) will lead her to deny that the implicitly offered perceptual evidence for (A1) is evidence: she will deny that perceptual newspaper-headline experience gives one any reason whatever to suppose that either newspapers or the events they mention really exist. 
I think what the example shows is that we need to relativise the notion of question begging to particular audiences, or to audiences with particular background beliefs, or to the context of utterance, or some such. For Jackson, as I said, a question begging argument is one such that anyone sane who doubted the conclusion would not be in a position to take one of the premises to be warranted. But such an absolute conception of question begging leaves us unable to diagnose (A)'s failure to convince the sceptic. So we need to say instead that an argument begs the question against a particular audience just if that audience is such that their reasons for doubting the conclusion compromise the warrant you implicitly offer them for the premises.

It seems right to say, then, that (A) begs the question against the sceptic; although not, of course, against someone who, prior to hearing the argument, doubts the conclusion for more mundane reasons (e.g. because she believes that North Melbourne are a much better team, and she hasn't seen the Grand Final). Such a person's reasons for doubting (A3) do not cast doubt on the ability of perceptual experience to furnish us with information about newspaper headlines. Hence such a person is entitled to "borrow" that perceptual evidence from the person putting forward the argument; and hence such a person may be persuaded by hearing (A) to believe (A3).

Notice, then, that warrant can be transferred from (A1) and (A2) to (A3): someone who is warranted in believing (A1) and (A2) will thereby be warranted in believing (A3). Of course, we cannot use this feature of (A) to convince the sceptic, since the sceptic will not agree that (A1) and (A2) are warranted; but that is precisely the point: (A) fails to convince in one sense (in the context of running the argument to a sceptic) 
but not in the other. That is, (A) fails to convince the sceptic insofar as it is question begging against the sceptic; but this failure is not a failure to transmit warrant, since from the sceptic's point of view the premises are not warranted. On the other hand, (A) might easily convince a non-sceptic who, in the process of hearing the argument, "borrows" the speaker's evidence for the premises and thereby comes to have warrant for the conclusion.

What (A) shows, then, is that the two senses of failure to convince can come apart; hence one cannot use the fact that (M) fails to convince in one sense to motivate the claim that it fails to convince in the other sense. ${ }^{3}$

\section{Does (M) fail to transmit warrant?}

Of course, for all I have said so far, (M) may yet fail to convince in the sense that one may not use it to transfer warrant from premises to conclusion: all I have shown is that failure of warrant transfer does not follow from (M)'s failure to convince a sceptic. If there were good reason to hold that (M) does fail to convince in this sense, then perhaps its failure could be used to motivate the First Limitation Principle. And Davies does indeed present independent reasons for thinking that $(\mathrm{M})$ cannot transmit warrant from premises to conclusion.

Davies' reasons come from a discussion of Wittgenstein's On Certainty. He says:

\footnotetext{
${ }^{3}$ Of course, there is $a$ sense in which an argument $\mathrm{X}$ that begs the question against $\mathrm{Y}$ is, a fortiori, an argument such that $X$ fails to transmit warrant for $Y$, since $X$ will not take herself to have any warrant to transfer: she is not in a position to be able to transfer warrant. But the sense of ' $\mathrm{X}$ fails to transmit warrant' that both Davies and I are interested in is a sense that takes it for granted that $\mathrm{Y}$ does take herself to have warrant for the premises, but is not entitled to transfer that warrant to the conclusion.
} 
What we have from Wittgenstein ... is a form of argument that proceeds from some workaday proposition, via a readily known entailment, to a proposition that belongs to 'the scaffolding of our thoughts' ... justification (or epistemic warrant) cannot be transferred from the workaday proposition via the known entailment to the scaffolding proposition. Thus ... I do have a justification for believing

Tree(1) My friend in New York has a ... tree in his garden

- a justification that is furnished by what my friend has told me about the buds, and so on, in our telephone conversation. And I can readily know

Tree(2) If my friend in New York has a ... tree in his garden, then the earth exists.

But that does not result in my having a justification for believing the conclusion:

Tree(3) The earth exists.

Nor, according to Wittgenstein, do I need any such justification. $(1998,349)$

The idea here, then, is that propositions like (M3) and Tree(3), because they belong to 'the scaffolding of our thoughts' - or, as Wright (1985) puts it, they lie outside the domain of 'cognitive achievement'- simply do not admit of justification. Since (M3) functions as a 'kind of presupposition of the justificatory, or epistemic, project' $(1998,350)$, it cannot itself admit of any justification.

What are we to make of Davies' appeal to Wittgenstein? Well, the first point that needs to be made is that the appeal can only provide motivation for the First Limitation Principle to the extent that we buy Wittgenstein's claim that propositions

Thus construed, the fact that $\mathrm{X}$ begs the question against $\mathrm{Y}$ does not entail that $\mathrm{X}$ fails to transmit warrant for $\mathrm{Y}$; rather, it entails that $\mathrm{Y}$ is not in a position for the issue of transfer of warrant to arise. 
like (M3) lie outside the realm of justification. And certainly many anti-sceptical philosophers are inclined to deny this claim, holding that we have every reason - in the full-blooded, epistemological sense of "reason" - to believe in the existence of the external world. No such philosopher will be convinced by Davies' appeal to Wittgenstein, since once we abandon the claim that (M3) cannot be justified, we no longer have any reason to concur with Davies that justification cannot be transferred to (M3) by (M1) and (M2).

The second point is that even if Davies is right about the status of (M3), and hence right to say that justification cannot be conferred upon it, no interesting general moral about arguments - like the First Limitation Principle - ought to be drawn. If (M3) cannot be justified, then of course it follows that justification cannot be transferred to it by (M); but that follows simply from the status of (M3), and not from any interesting feature of $(\mathrm{M})$.

My argument so far has been designed to show that FLP is not motivated by what Davies says about (M) and about On Certainty: he gives no reason to suppose that there is some interesting general principle which limits the transfer of warrant from premises to conclusion of arguments like (M). But perhaps Davies' claim still has some intuitive force behind it. Consider two rhetorical questions, which he quotes from On Certainty:

208. I have a telephone conversation with New York. My friend tells me that his young trees have buds of such and such a kind. I am now convinced that his tree is . . . Am I also convinced that the earth exists? 
210. Does my telephone call to New York strengthen my conviction that the earth exists? $(1998,348)$

The answer we are inclined to give, of course - and the answer Wittgenstein wants us to give - is "no". It seems absurd to suppose that we can legitimately strengthen our belief in the existence of the earth by observing our hands, trees, and other objects in our environment. But if we deny that there are any principled limits on transfer of warrant, aren't we committed to precisely that absurd supposition? Well, no. We can perfectly well agree with Wittgenstein that observing my own hands does not, as a matter of psychological fact, strengthen my conviction that the external world exists, without committing ourselves on the issue of whether observation of my hands warrants (M3).

Of course, we can now pose another question to which it might be thought that a positive answer is just as absurd as it is in the case of Wittgenstein's questions: Does my observation of my hands confer warrant on my belief that the earth exists? If we deny that there are limits on transfer of warrant, it seems that we have to answer, “yes".

Well, perhaps it does seem absurd to say that I might start out with a certain amount of warrant for (M3) and then, by running (M), end up with more warrant for it than I had before. However, I can think of three different views one might take on the issue, none of which points towards the need for limitation principles. It might be that none of the views is viable; but it needs to be shown that none is viable if the need for limitation principles is to be established. 


\section{(i) The ceiling effect}

The first view is that we can explain why warrant can't be transferred from the premises to the conclusion of $(\mathrm{M})$ - without the aid of a limitation principle - by appealing to a sort of "ceiling effect". Grant that the proposition that the external world exists does not lie outside the "domain of cognitive achievement": grant, in other words, that it is a proposition for which we can (and do) have evidence. And grant further that the kind of evidence we have for it is broadly perceptual. Then it may well be that ordinary, non-sceptical folk like us already have about as much warrant for (M3) as we can get. We have all of us had a stupendously large number of perceptions of and interactions with the external world; and extra observations just aren't going to increase our warrant any further. 49 year olds do not in general have any more reason to believe in the external world than 31 year olds; so it's not surprising that one measly perception of a hand - that is to say, the warrant for (M1) doesn't make any difference at all to our warrant for (M3). In other words, it might be that there is a kind of "ceiling effect": there's a point at which perceptual experience stops bumping up our warrant for (M3).

Of course, those who are of a more sceptical turn of mind might not take themselves to have as much warrant as they could wish for (M3): they might take themselves to have very little warrant for it; or perhaps even none at all. Does that mean that we need a principle limiting transfer of warrant in order to explain why they cannot transfer warrant from the premises to the conclusion of $(\mathrm{M})$, since they haven't reached the ceiling that the rest of us take ourselves to have reached? No. We already know that no such principle is needed in order to deal with the sceptic. (M) begs the 
question against the sceptic; hence she will not take herself to have warrant for (M1) either; and hence the question of whether she may transfer warrant from (M1) to (M3) does not arise.

To clarify the point, consider, by way of an analogy, my warrant for the sentence

$$
\sim(\mathrm{P} \vee \mathrm{Q}) \equiv(\sim \mathrm{P} \& \sim \mathrm{Q})
$$

There are many ways of proving $(\mathrm{T})$. We might use any one of a number of different systems of propositional logic, using any number of different specific proofs; or truth tables; or tableaux; and so on. But I am already as sure as sure can be of the truth of (T). No proof of it, if presented to me or if run through in my own head, will increase my warrant for it one jot. Indeed it would seem quite absurd to suggest that my warrant for $(\mathrm{T})$ ought to increase with each new proof that is presented to me.

So it seems that there is a ceiling effect with (T): further arguments that have (T) as a conclusion will not improve my warrant for it. Now, the right thing to say about (T), it seems to me, is that although in fact I cannot transfer warrant from the premises of any argument to the conclusion that $(\mathrm{T})$, because of the ceiling effect, such arguments can, in principle, be used to transfer warrant across to $(\mathrm{T})$. We can imagine beings first year logic students, for example - obtaining warrant for (T) by, for instance, proving it to themselves.

The question now arises: in the absence of any limitation principles, can we imagine beings for whom the issue of transfer of warrant arises with respect to (M)? Such beings would have to have failed somehow to reach their evidential ceiling; and they 
would also have to take themselves to have warrant for (M1) - so sceptics don't count.

I myself am unsure about whether or not there could be such beings. Luckily, however, no substantive relevant philosophical issue seems to turn on the answer. If such beings are impossible, then the issue of transfer of warrant simply doesn't arise in the case of $(\mathrm{M})$ - since anyone trying to run $(\mathrm{M})$ as a way of getting warrant for (M3) will find either that they don't take (M1) to be warranted to start with, or that (M3) is already maximally warranted. If, on the other hand, such beings are possible, then perhaps the issue of transfer of warrant does arise in the case of $(\mathrm{M})$ - for those beings. So perhaps we could decide whether those beings are entitled to transfer warrant across to (M3) by running the appropriate thought experiment and testing our intuitions. But it seems to me that any such thought experiment will be sufficiently far removed from the situation in which we actual human beings find ourselves to render any intuitions we might have about their entitlement to transfer warrant untrustworthy. Moreover, it is far from clear that we need to concern ourselves with such peculiar beings in any case. What we care about are beings like us - and for us, whether we are sceptics or not, the issue of transfer of warrant does not arise for (M) if warrant is subject to a ceiling effect.

\section{(ii) Arguing to an audience and arguing to oneself}

The second and third possible views of the issue of warrant transfer in the case of (M) concern not $(\mathrm{M})$ in particular but rather the more general issue of how the notion of transfer of warrant might apply to arguments which one runs in one's own head. 
On Jackson's view of the purpose of arguing, arguing has two basic functions. One is the "teasing out" function, which basically amounts to proving something to somebody who already had the resources to do it themselves in the first place - in other words, showing them how propositions that they already believe entail other propositions that they hadn't previously recognised as consequences of what they already believed. The other function of arguing is the evidence-borrowing function: in presenting an argument, the speaker advertises herself as having a certain sort of evidence for the premises which the hearer may not possess. Hearing the argument enables the hearer to "borrow" that evidence, thereby coming to have warrant for the premises and a fortiori for the conclusion.

Now, Jackson's concern is with argument as a public activity: with the activity of presenting an argument to an audience. However, with the distinction between teasing-out and evidence borrowing in place, it is worth noting an important disanalogy between $(\mathrm{M})$ on the one hand and arguments like (A) on the other: $(\mathrm{M})$, unlike (A), is essentially a first-personal argument.

When we read Moore's argument for the existence of the external world, the point is not that we, the audience, should become convinced of (M3) because we are convinced that Moore is warranted in believing that he has a hand which he is holding in front of his face: we are not being asked to take Moore's word for (M1), as written or spoken by him, and thereby to acquire (or acknowledge that we have) warrant for (M3). Rather, the point is that the argument is one that we can use for ourselves: the evidence for (M1) is evidence for (M1) as thought by us. Indeed the evidence for 
(M1) is supposed to be so convincing precisely because it consists of our own perceptual experience and not someone else's.

In the current context, what is important about "first-personal" arguments - that is, arguments which one runs in one's own head - is that the only function of running an argument in one's own head can be the teasing-out function: in the first-personal case the question of evidence borrowing does not arise, since one cannot borrow evidence from oneself.

Now, given that $(\mathrm{M})$ is a first-personal argument, we can set aside the question of when or whether warrant is transferred in the case of arguments where evidence borrowing is in play, and ask whether, if I run an argument in my head (for the purpose of teasing out), I in general transfer warrant from its premises to its conclusion. Well, here are the remaining two views of the three I promised: according to one, the answer is "yes", and according to the other, the answer is "no".

On the one hand, it might be thought that when one discovers that a particular proposition follows from other propositions which one warrantedly believes, one does not really acquire any extra warrant for the conclusion; one merely comes to realise that the conclusion was warranted all the time. We can imagine someone who's simply never even entertained the proposition that the external world exists before suddenly realising that it follows from (M1) and (M2) - and hence coming explicitly to believe warrantedly that the external world exists. But it doesn't seem implausible to say that what changes when she runs the argument is not that (M3) gets warranted, but rather that she comes to realise that (M3) was warranted all along, or that what 
she acquires is an explicit belief that she didn't have before rather than warrant that she didn't have before.

If this is the right thing to say about arguments that are run in one's own head in general, then, although arguments like (M) will thereby fail to transmit warrant, they will fail not because there are any limitation principles at work, but simply because of the fact that teasing out does not in general result in transmission of warrant.

That's the "no" answer. But the "yes" answer doesn't seem so bad either. We can imagine someone suddenly being struck by the realisation that she believes that the external world exists, and wondering (without having any sceptical doubts in mind) whether that belief is warranted. She then reflects on the fact that she does take herself to be warranted in believing that she has hands, and on the fact that her having hands entails that the world exists, and thereby satisfies herself that she does have warrant for believing (M3). And we might want to count this as a case of warrant transfer. If this is the right thing to say, then we do not need any limitation principles because there is nothing wrong with accepting that warrant may be transferred from (M)'s premises to its conclusion.

None of the three views described above points towards any need for limitation principles of the kind suggested by Davies. Hence denying that there are any principled limitations on the transfer of warrant does not obviously commit us to anything crazy. 


\section{The Second Limitation Principle - and how (W) begs the question}

With all this in place, it's high time we got onto the issue of semantic externalism and first person authority to see whether similar considerations can be brought to bear on that debate. So here's Davies' Second Limitation Principle:

\section{Second Limitation Principle:}

Epistemic warrant cannot be transferred form A to B, even given a priori known entailment from $A$ to $B$, if the truth of $B$ is a precondition of the knower even being able to believe the proposition A. $(1998,353)$

The crucial difference between the First and Second Limitation Principles is that while the First Limitation Principle blocks the transfer of warrant when the truth of the conclusion is a precondition of the knower's warrant for one of the premises to count as warrant, the Second Limitation Principle does it for arguments whose conclusions need to be true in order for the knower to even be able to entertain one (or both) of the premises. In the case of (W) - assuming that semantic externalism is true - I cannot even think water thoughts - and hence cannot think that I am in a water world - unless I actually do live in a water world.

Now, the force of (W) as an objection to the combination of semantic externalism and first person authority is the thought that there ought not to be a way of arriving at empirical knowledge without getting up from one's armchair. I can know (W1) and (W2) without getting up from my seat - by introspection and conceptual analysis respectively - yet I ought not thereby to be able to know (W3), since (W3) is a proposition that can only be known by empirical investigation. Davies' solution to the 
problem, as we've seen, is to deny - via the Second Limitation Principle - that our warrant for (W1) and (W2) can be transferred across to (W3); so there is no possibility of being able to acquire warrant for (W3) without getting up and doing some empirical investigation.

What I'll try to do in this section is show that what goes for (M) goes for (W) as well: either the issue of transfer of warrant does not arise in the first place, or, if it does, there is no real reason to think that warrant cannot be transmitted.

So, as with (M), we need to ask what kind of person might doubt (W3). The easiest case is that of the Cartesian sceptic, who believes that all her perceptual experiences and a fortiori those experiences that lead her to believe that water exists - might, for all she knows, be the work of an evil demon. The true Cartesian sceptic will doubtless take herself to be warranted in believing (W1) - she will take herself to know what she is thinking - it's just that she will doubt whether any of the judgements she makes about, say, the existence of water are actually true. But she will have no truck with semantic externalism. One of her reasons for doubting (W3) is the alleged intelligibility of the demon hypothesis; but semantic externalism renders such a hypothesis unintelligible. When one imagines a demon world, one imagines a world where the contents of one's beliefs remain the same but the nature of the external world is dramatically different to the way one believes it to be; and the coherence of the imagined scenario is undermined by the claims of semantic externalism. Hence (W) begs the question against the Cartesian sceptic: her reasons for doubting (W3) will leave her unable to countenance any argument for the truth of (W2). 
Here's another line of thought that might lead one to worry about one's warrant for (W3). Imagine that I am moved by Twin Earth thought experiments to entertain a certain kind of sceptical doubt. "Gosh", I think to myself, "my having the concept water requires there to be water in my environment. There is no water - only XYZ in Twin Helen's environment; but Twin Helen's state of mind seems just the same to her as mine does to me. So I really have no reason at all to think that $I$ live in a water (as opposed to a twater) world".

Were I to run such a line, I would unfortunately be merely confused about the implications of semantic externalism. The content of my concept water is determined by whatever natural kind I am in fact acquainted with, whether it is $\mathrm{XYZ}$ or $\mathrm{H}_{2} 0$; and either way I have every reason to think that the sentence "I live in a water world" as uttered by me is true. So we don't need to worry about that kind of doubt about (W3).

The doubts about (W3) I've mentioned so far are doubts that are inconsistent with the claims of semantic externalism, and hence doubts that anyone who took themselves to have warrant for (W2) would not be in a position to entertain. But there is another way of doubting (W3) which is not inconsistent with the claims of externalism; for one does not need to have a Cartesian conception of the mind in order to be a sceptic. Externalism certainly makes scepticism rather difficult to formulate coherently; but it does not rule it out altogether, for externalism makes no empirical claims about the actual constitution of the world. Given that externalism is consistent with external world scepticism - or, more modestly, scepticism about the existence of water - then there ought to be some sceptical hypothesis, analogous to the demon hypothesis, which a semantic externalist can entertain. 
The problem with formulating such a hypothesis is, of course, that since being in a water world is a precondition of having the concept water, I cannot rationally entertain the thought that I do not live in a water world - since that thought makes use of a concept that I can only possess if I do live in a water world. So at this point I'm going to modify a suggestion of Crispin Wright's and formulate the relevant sceptical hypothesis thus:

(P) The seeming-thought which I attempt to express by "I live in a water world" is content-defective owing to the reference failure of the purported natural kind term, “water”, in my language. (See Wright (2000), **)

Now, the issue of what exactly it would take for "water" to fail to refer is a tricky one, since it depends on precisely what one thinks semantic externalism amounts to. But I'm going to gloss over that issue. Just imagine that you have in mind some possible scenario, subjectively indistinguishable from the one you actually take yourself to be in, in which your environment is such as to render your seeming-thought "I live in a water world" content-defective.

Now imagine a semantic externalist who is of a sceptical turn of mind: someone who is inclined to take sceptical hypotheses in general - if they are coherent - to seriously undermine her knowledge claims. In the case of $(\mathrm{M})$, the Cartesian sceptic takes the demon hypothesis (say) to undermine her warrant for (M3) (and a fortiori for (M1)). However, in the case of (W), the situation is rather less straightforward, since someone who takes $(\mathrm{P})$ seriously will take it to undermine not simply her warrant for 
(W3), but rather her ability to think (W3) at all. The Cartesian sceptic might, in the face of the demon hypothesis, accept (M3) for practical purposes despite its lack of warrant, or perhaps might decide not even to accept (M3) for practical purposes, while still being able to adopt propositional attitudes - like doubt - towards it. But the externalist sceptic cannot take herself to have the ability to adopt such attitudes towards (W3), since that ability presupposes that she is able to entertain (W3) at all and this possibility is precisely what $(\mathrm{P})$ casts doubt on.

However, this does not preclude us from describing the sceptic's epistemic situation as being that of having her warrant for (W3) undermined by $(\mathrm{P})$. For the sceptic can reason as follows: "Either the seeming-thought I attempt to express by "I live in a water world" is content-defective - in which case I do not warrantedly believe (W3), since it does not express a genuine thought and hence is not the sort of thing that could be warranted; or the seeming-thought "I live in a water world" is a genuine thought. But this possibility and the possibility that $(\mathrm{P})$ is true are subjectively indistinguishable from one another. I cannot take myself to warrantedly believe something if I cannot even tell whether or not I believe it; hence I do not have warrant for (W3)."

So far so good. But now consider the attitude that our sceptic is rationally required to take towards (W1). Just as (W3) has the subjectively indistinguishable correlate (P), so (W1) has the subjectively indistinguishable correlate $\left(\mathrm{P}^{*}\right)$ : 
(P*) The seeming-thought which I attempt to express by "I am having a water thought" is content-defective owing to the reference failure of the purported natural kind term, “water”, in my language.

Since our sceptic takes the subjective indistinguishability of (P) from (W3) to undermine warrant for (W3), she is rationally required to take the subjective indistinguishability of $\left(\mathrm{P}^{*}\right)$ from (W1) to undermine warrant for (W1), in precisely the same sense and for precisely the same reasons. Hence the sceptic's reasons for not taking herself to have warrant for (W3) also undermine any warrant (namely first person authority) she might antecedently have taken herself to have for (W1). So (W) begs the question against our externalist sceptic.

The point here, again, is not that, since the sceptic takes (W2) to be warranted but (W3) to be unwarranted, she is rationally compelled to take (W1) to be unwarranted. This is true, but it does nothing to show that (W) begs the question against her. Rather, it is that her reasons for taking (W3) to be unwarranted - namely, her belief that the possibility of (P) undermines her claim to have warrant for (W3) - are $a$ fortiori reasons to take (W1) to be unwarranted, just as the Cartesian sceptic's reasons for doubting (M3) are a fortiori reasons for doubting (M1).

Now, what I hope to have shown so far is that (W) begs the question against a range of possible doubters of (W3). Hence the issue of transfer of warrant does not arise for such doubters. But what about people like you and me, who do not have any principled reasons for doubting the conclusion? Can we transfer warrant across from (W1) and (W2) to (W3)? 
Well, recall the three options I discussed earlier with respect to (M). I'm not sure that a convincing case can be made that there is a "ceiling effect" for (W3) (although I also can't think of any reasons why there shouldn't be such an effect). So I set that option aside.

That leaves us with the issue about what to say about warrant transfer in cases of teasing-out. (Note that $(\mathrm{W})$ is even more clearly a first-personal argument than $(\mathrm{M})$ is; hence the only reason to use (W) can be for the purposes of teasing-out.) If we decide that teasing-out doesn't in general result in warrant transfer, then fair enough: what goes in general goes for (W) in particular. Hence there is no need for a principle aimed at specific kinds of argument in order to explain why warrant is not transferred in the case of $(\mathrm{W})$. On the other hand, if we decide that warrant can be transferred in teasing-out cases, then I see no reason why we shouldn't say that warrant is transferred in the case of (W). In a recent paper, Sarah Sawyer says:

... it must be recognised that introspection will yield knowledge only of those empirical facts that the subject could already have come to know via empirical means. Here it is worth reflecting on the function of memory. As I am, at the present moment in time, I can 'look inside my mind' and produce various pieces of empirical knowledge: for instance, that the battle of Hastings was fought in 1066. Why are people willing to accept memory as a route to empirical knowledge? Presumably because memory is recognised as a way of retrieving information which was acquired via empirical means at an earlier time, even if the means by which it was acquired can themselves no longer be remembered. Semantic memory is of this type. I may be unable to recollect when and how I learnt certain of the concepts I possess, 
but this does nothing to impugn my knowledge of those concepts. Instance arguments [i.e. arguments like (W)] similarly yield knowledge of facts which at an earlier point in time were acquired empirically. This is not, however, to say that instance arguments do not yield new knowledge. They do. They yield new knowledge in just the say way that deductive arguments generally yield new knowledge: they clarify the consequences of the knowledge we already have. (Sawyer 1998, 532-3)

It seems to me that the notion of "clarifying the consequences of the knowledge we already have" is roughly the same as Jackson's notion of the "teasing-out" function of arguments. If warrant can, in general, be transferred in arguments that perform this function, I see no reason why we should not simply accept that warrant is transferred in the case of arguments like (W). (This is not to say, of course, that we can run (W) thorough in our heads every morning and thereby gradually acquire more and more warrant for (W3) without ever getting our hands wet. Once the teasing-out function of (W) has been performed, no further purpose can be served by running (W) again unless one's memory is very bad.)

\section{An objection disarmed}

Up to now, I've been framing the transfer of warrant issue in terms of running an argument in one's own head and asking whether or not the warrant that one has for the premises is "transferred" or "transmitted" to the conclusion. This way of talking suggests that what we're interested in is what might be called the "dynamics" of warrant: the issue of how warrant "flows" from one belief to another.

However it might reasonably be objected that this "bucket theory" of warrant transfer is not really what the debate over semantic externalism and first person authority (and 
a fortiori the debate about Moore's argument) is really about. One might claim that the debate about $(\mathrm{W})$ is really a debate about warrant qua rational justification, so that what's important is not whether or not we might in fact come to acquire warrant for (W3) by way of (W), but whether, in the case where we take ourselves to have warrant for (W3) already, we could, if called upon, justify our belief in (W3) by making use of (W). To see the distinction, think of (T): how I in fact acquired my warrant for (T), and whether or not (T)'s "warrant bucket" is full, is not relevant to the issue of whether I could, if called upon, use a particular proof as a justification for $(\mathrm{T})$.

My response to this objection is to appeal to something like David Lewis's view in 'Elusive Knowledge' (1996) of the context-relativity of knowledge, and to claim that whether one has successfully justified a claim is a context-relative matter. If I try to justify my belief that, say, Martin is flying to Melbourne tonight, I can do it by appealing to the fact that he told me he was going. If I press the issue and ask myself how I know he wasn't lying, I might require - and be able to give - some further justification; I might, for instance, point out to myself that Martin doesn't usually (so far as I know) lie about such matters, and that I can't think of any special reason why he should do so on this occasion. But I might push myself still further, and entertain the possibility that the person currently at the RSSS is not Martin at all but his evil twin, or the possibility that this is all just a big dream and Martin is still safely ensconced in Oxford. If I consider these possibilities, I might well run out of justificatory resources. Relative to the dream possibility, say, I cannot justify my belief that Martin is flying to Melbourne. And we can tell a begging-the-question story about why my previous justification no longer cuts the mustard: once I doubt 
the veridicality of my recent sensory experiences, the kinds of argument I just advanced to the conclusion that Martin is flying to Melbourne will not allay my fears, since those arguments invoked premises that were warranted by the reliability of my sensory experience, which is precisely what I am currently calling into question.

I claim that there is a similar story to be told about (W). One way of justifying (W3) to myself is to reflect on the fact that I can entertain water thoughts, and the fact that in order for me to be able to do that, I must live in a water world. If I raise the stakes and entertain the possibility that my seeming-thought "I live in a water world" is content-defective, I can no longer offer the justification just given, since once I take that possibility seriously I am no longer in a position to take myself to have first person authority about what I'm thinking. Relative to the envisaged sceptical scenario, I cannot tell "from the inside" whether I am really thinking anything at all.

Now, you might still not be convinced that in the normal, non-sceptical case I really can invoke (W) as a way of justifying (W3): evidently this is a piece of bullet-biting which most people seem unwilling to accept. But if you don't like it, you have to come up with a persuasive story about what exactly is wrong with invoking (W) in the service of justifying (W3). And one story that won't be persuasive is one which points out that (W) will not assuage sceptical doubts. When sceptical possibilities are not in play, the fact that a particular purported justification does not rule those possibilities out does not undermine its justificatory status.

\section{Conclusion}


The central theme of this paper has been the claim that we need to separate issues about begging the question from issues about transfer of warrant. Once we agree that (W) cannot justify (W3) in a way that assuages any principled doubts about the thinkability of (W3) - and I've argued that (W) can't do this because it begs the question against such doubts - we can happily accept that (W) does justify (W3) in ordinary, everyday, non-sceptical contexts. Or, if you don't like that last part, you can happily accept that warrant does not transfer across to (W3) - not because of any incompatibility between first person authority and semantic externalism, and not because there is some general principle that blocks transfer of warrant for arguments like (W), but simply because when an argument is used for teasing-out purposes, warrant is never transferred from premises to conclusion.

It might be argued that the position I am advocating is not really a compatibilist position at all. After all, I argued in section 4 that the kind of sceptical doubt a semantic externalist might entertain about the thinkability of (W1) will undermine her claim to have first person authority about what, if anything, she is thinking. But surely first person authority, at least in its most full-blooded sense, is supposed to be a priori and therefore not susceptible to doubts stemming (as doubts about the thinkability of (W1) do) from doubts about the constitution of the external world. So it seems that I am repudiating first person authority after all, and hence accepting, rather than rejecting, the incompatibilist's claim.

But a priori justification is not in any case justification that survives any sceptical doubt whatever. If we doubt our sanity, or entertain the possibility that the evil demon is interfering not just with our sensory experiences but also with our reasoning 
processes, even our warrant for basic arithmetical propositions, say, or logical principles is undermined: a priori justification cannot survive principled doubts about the workings of our own minds. And such doubts might easily stem from consideration of hypotheses about the external world - the hypothesis that the demon is messing with my reasoning, for example.

Our hypothetical externalist sceptic is in a similar, though less epistemically catastrophic, position. Knowing that her ability to think certain thoughts depends upon contingent features of the world, and persuaded that there is a possible scenario that is subjectively indistinguishable from the situation she ordinarily takes herself to be in where those features do not obtain, she loses confidence in that ability: she does not take herself to have first person authority about what, if anything, she is thinking.

But the externalist sceptic's loss of faith in first person authority should not concern those of us who, for whatever reason (so long as it is a good one), are unimpressed by the effect of imagined subjectively indistinguishable scenarios on our knowledge claims. If we are unmoved by scepticism in general, then the externalist sceptic's loss of faith does not in the least undermine our claim to have first person authority any more than the radical sceptic's loss of faith in logical principles should undermine our claim that those principles are a priori justified. So long as we keep sceptical hypotheses at bay, we can happily hold on to both semantic externalism and first person authority - without invoking any limitation principles.

\section{Bibliography}


Davies, M. (1998): 'Externalism, Architecturalism, and Epistemic Warrant' in C. Wright, B.C. Smith \& C. Macdonald (eds.), Knowing Our Own Minds. Oxford: Clarendon Press; 321-361

Jackson, F. (1987): Conditionals. Oxford: Basil Blackwell

Lewis, D.K. (1996): 'Elusive Knowledge', Australasian Journal of Philosophy 74, $549-567$

Sawyer, S. (1998): 'Privileged Access to the World', Australasian Journal of Philosophy 76, 523-533

Wittgenstein, L. (1969): On Certainty (ed. G.E.M. Anscombe \& G.H. von Wright). Oxford: Basil Blackwell

Wright, C. (1985): 'Facts and Certainty', Proceedings of the British Academy 71, $429-472$

Wright, C. (2000): 'Cogency and Question-Begging: Some Reflections on McKinsey's Paradox and Putnam's Proof', Philosophical Issues 10, 140-163 